\title{
FAKTOR-FAKTOR YANG BERHUBUNGAN DENGAN PERILAKU IBU DALAM PEMBERIAN ASI EKSKLUSIF
}

\author{
Suzana Indragiri*
}

\begin{abstract}
ABSTRAK
Menyusui merupakan suatu pengambilan keputusan yang sangat bijaksana dari kedua orang tua. ASI merupakan makanan terbaik dan paling cocok untuk bayi yang dapat menjamin pertumbuhan bayi menjadi manusia yang berkualitas, karena mengandung zat gizi yang sesuai dan optimal bagi tumbuh kembang bayi. Penelitian ini bertujuan untuk mengetahui faktor-faktor yang berhubungan dengan perilaku ibu dalam pemberian ASI Eksklusif di Kelurahan Kesenden Wilayah Kerja UPTD Puskesmas Kejaksan Kota Cirebon tahun 2013. Metode penelitian yang dilakukan adalah deskriptif analitik dengan pendekatan yang bersifat studi cross sectional. Populasi dalam penelitian ini adalah seluruh ibu yang memiliki bayi umur 7- 24 bulan yang datang ke Posyandu sebanyak 340 bayi. Sampel adalah ibu yang memiliki bayi umur 7-24 bulan sebanyak 75 orang yang dipilih berdasarkan metode proportionate random sampling. Pengumpulan data dilakukan dengan pengisian kuesioner.Hasil penelitian menunjukkan bahwa berdasarkan hasil uji statistik (uji chi square) menunjukkan bahwa terdapat hubungan bermakna antara pengetahuan ibu ( $p$ value : 0,000$)$, keterpaparan informasi ibu ( $p$ value: 0,003$)$ dan dukungan keluarga ( $p$ value: 0,004$)$ dan didapat pula hasil yang tidak berhubungan antara pendidikan ( $p$ value: 1,000), pekerjaan ibu ( $p$ value: 0,698$)$ dan dukungan tenaga kesehatan $(p$ Value: 1,000$)$ dengan perilaku ibu dalam pemberian ASI Eksklusif di Kelurahan Kesenden Wilayah Kerja UPTD Puskesmas Kejaksan Kota Cirebon Tahun 2013.
\end{abstract}

Kata Kunci : $\quad$ Faktor-faktor, perilaku ibu, ASI eksklusif

\begin{abstract}
Breastfeeding is a very wise decision from both parents. Breast milk is the best and most suitable food for babies who can guarantee the growth of a quality human babies, because it contains the appropriate nutrients for optimal growth and development of infants. This study aimed to determine the factors associated with exclusive breastfeeding mother's behavior in the Village Kesenden Work Areas UPTD Kejaksan Cirebon City Health Center in 2013. The research method is a cross sectional study. Population in this research were mothers whi come in the result of infants aged 7-24 months as many as 340 mother. Samples were mothers of infants aged 724 months as many as 75 people were selected based on proportionate random sampling method. Data was collected through questionnaires. The results showed that based on the results of the statistical test (chi square test) showed that there is a significant relationship between maternal knowledge ( $p$ value: 0.000 ), maternal exposure information ( $p$ value: 0,003$)$ and family support ( $p$ value: 0.004$)$ and also the results obtained are not related between education ( $p$ value: 1,000), maternal employment ( $p$ value: 0.698$)$ and support health workers $(p$ value: 1.000) with the behavior of the mother in breastfeeding Eksklusif di Kesenden work Area Urban health Center Kejaksan UPTD Cirebon Year 2013. Advice to Cirebon City Health Department provides media-related IEC exclusive breastfeeding, to enable health workers to be more intensive re-education breastfeeding, to immediately consult public health services (clinics lactation) for mothers who have problems lactating or breastfeeding.
\end{abstract}

Keywords : Factor-factor, maternal behavior, exclusive breastfeeding.

\footnotetext{
* Staf Pengajar Program Studi S1 Kesehatan Masyarakat STIKes Cirebon
} 


\section{PENDAHULUAN}

Tujuan Pembangunan millennium atau Millennium Development Goals (MDGs) mengusung tiga tema utama, yaitu pembangunan manusia, keamanan dan hak asasi manusia. Kerangka MDGs merupakan salah satu upaya untuk menyamakan visi global yang kemudian diterjemahkan ke dalam aksi-aksi pembangunan lokal. Konsep MDGs pada intinya bertujuan untuk membawa pembangunan kearah yang lebih adil bagi semua pihak, bagi manusia dan lingkungan hidup, bagi laki-laki dan perempuan, bagi orang tua dan anak-anak, serta bagi generasi sekarang dan generasi akan datang. ${ }^{1}$

Menyusui merupakan suatu pengambilan keputusan yang sangat bijaksana dari kedua orang tua. Banyak keuntungan yang didapat dari pemberian ASI (Air Susu Ibu). Baik keuntungan untuk bayi, ibu, keluarga dan lingkungan bahkan untuk perekonomian nasional. ASI merupakan makanan terbaik dan paling cocok untuk bayi yang dapat menjamin pertumbuhan bayi menjadi manusia yang berkualitas, karena ASI mengandung zat gizi yang sesuai dan optimal bagi tumbuh kembang bayi tersebut. ${ }^{2}$

Indonesia memiliki komitmen untuk melaksanakan "Deklarasi Innocenti” tahun 1990 yang menyatakan bahwa setiap Negara diharuskan memberikan perlindungan dan dorongan kepada ibu agar berhasil memberikan ASI secara eksklusif kepada bayinya. Dukungan Indonesia untuk Deklarasi Innocenti 1990 (Italia) tersebut antara lain dengan pencanangan Gerakan Nasional PP-ASI (Peningkatan Penggunaan ASI) oleh Presiden pada tahun 1990 dan terbentuknya Rumah Sakit Sayang Bayi pada beberapa Rumah Sakit Pemerintah dan Swasta. Sampai saat ini Indonesia telah memiliki Keputusan Menteri kesehatan (Kepmenkes) No. 237/1997 tentang Pemasaran Pengganti Air Susu Ibu dan No.450/2004 tentang Pemberian Air Susu Ibu secara Eksklusif pada bayi di Indonesia, yang mengatur mengenai masalah pemberian ASI di Indonesia. ${ }^{2}$

ASI adalah makanan terbaik dan paling sempurna untuk bayi, karena mengandung semua zat gizi yang sesuai kebutuhan untuk pertumbuhan dan perkembangan bayi. Bayi yang tidak diberi ASI berarti tidak mendapat makanan yang bergizi dan berkualitas tinggi sehingga akan menghambat pertumbuhan dan kecerdasannya. Dampaknya bayi akan mengalami gangguan pertumbuhan dan menyebabkan berkurangnya jumlah sel-sel otak bayi sebanyak $15-20 \%$, sehingga menghambat perkembangan dan kecerdasan bayi pada tahap selanjutnya yang dibiarkan lama kelamaan akan menimbulkan kematian bayi. ${ }^{3}$

Berdasarkan hasil survey Demografi Kesehatan Indonesia (SDKI) tahun 1997 terlihat bahwa bayi yang diberi ASI secara Eksklusif selama 6 bulan adalah 42,4 \%. Nilai ini ternyata lebih besar dibandingkan hasil data SDKI tahun 2002 yang menunjukkan prevalensi bayi yang mendapatkan air susu ibu secara eksklusif hanya $39,5 .{ }^{4}$

Di Cirebon tahun 2011 prevalensi bayi yang diberikan air susu ibu Eksklusif umur 0-6 bulan tanpa makanan tambahan sebesar adalah $21,8 \%$. Hal ini tidak sesuai dengan target yang telah ditetapkan oleh Departemen Kesehatan yaitu sebanyak $80 \%$ bayi harus mendapat air susu ibu Eksklusif. Hal ini menunjukkan bahwa cakupan Pemberian ASI Eksklusif di Kota Cirebon masih rendah. ${ }^{5}$

Berdasarkan Laporan Tahunan Puskesmas Kejaksan tahun 2011 diperoleh data bayi yang mendapatkan ASI Eksklusif 37,05\% sedangkan pada tahun 2010 bayi yang mendapatkan ASI Eksklusif sebanyak 48,19\% hal ini mengalami penurunan sebesar 11,14\%, di Kelurahan Kesenden masih jauh dari rata-rata dimana diketahui target yang diharapkan yaitu sebesar $80 \%$ bayi 0-6 bulan mendapat ASI Eksklusif sehingga terdapat kesenjangan $42,95 \%{ }^{6}$

Penelitian ini bertujuan mengetahui faktor-faktor yang berhubungan dengan perilaku ibu dalam pemberian ASI Eksklusif di Kelurahan Kesenden Wilayah Kerja UPTD Puskesmas Kejaksan Kota Cirebon tahun 2013. 


\section{METODE PENELITIAN}

Rancangan penelitian yang digunakan adalah penelitian deskriptif analitik dengan pendekatan Cross Sectional. Populasi pada penelitian ini adalah seluruh ibu yang memiliki bayi umur 7- 24 bulan yang datang ke Posyandu di UPTD Puskesmas Kejaksan Kelurahan Kesenden Kota Cirebon tahun 2013 yaitu sebanyak 340 bayi. Pengambilan sampel dengan menggunakan teknik proportional random sampling sehingga jumlah sampel sebanyak 75 responden. Instrumen dalam penelitian ini adalah kuesioner. Data primer dalam penelitian ini diperoleh dengan menggunakan cara angket. Analisis data dilakukan melalui analisis univariat dengan menyajikan distribusi frekuensi dan persentase dari tiap variabel. Sedangkan analisis bivariat yaitu untuk mencari hubungan variabel bebas ( pengetahuan, tingkat pendidikan, status pekerjaan, keterpaparan informasi, dukungan keluarga dan dukungan petugas kesehatan) dan variabel terikat atau perilaku ibu dalam pemberian ASI Eksklusif dengan taraf nyata $5 \%$.

\section{HASIL PENELITIAN}

\section{Perilaku Pemberian ASI Eksklusif}

Hasil penelitian menunjukkan bahwa ibu yang memberikan ASI secara eksklusif sebanyak 52 orang $(69,3 \%)$ sedangkan yang tidak memberikan ASI ekslusif sebanyak 23 orang $(69,3 \%)$.

\section{Pengetahuan, Tingkat Pendidikan, Status Pekerjaan, Keterpaparan Informasi, Dukungan Keluarga dan Dukungan Petugas Kesehatan}

Hasil penelitian menunjukkan bahwa ibu yang mempunyai pengetahuan baik tentang ASI Eksklusif sebanyak 51 orang (68\%), ibu yang mempunyai tingkat pendidikan rendah sebanyak 38 orang $(50,7 \%)$, ibu yang mempunyai kriteria tidak bekerja sebanyak 56 orang $(74,7 \%)$, ibu yang terpapar informasi tentang ASI Eksklusif sebanyak 66 orang (88\%), ibu yang mendapat dukungan dari keluarga untuk memberikan ASI Eksklusif sebanyak 63 orang (84\%) dan ibu yang mendapat dukungan dari tenaga kesehatan untuk memberikan ASI Eksklusif sebanyak 64 orang $(85,3 \%)$.

\section{Hubungan Pengetahuan Ibu tentang Pemberian ASI Eksklusif dengan Perilaku Ibu dalam Pemberian ASI Eksklusif}

Tabel 1. Hubungan Pengetahuan Ibu tentang ASI Eksklusif dengan dengan Perilaku Ibu dalam Pemberian ASI Ekslusif

\begin{tabular}{|c|c|c|c|c|c|c|c|c|}
\hline \multirow{3}{*}{ No } & \multirow{3}{*}{ Pengetahuan Ibu } & \multicolumn{4}{|c|}{ Perilaku Pemberian ASI Eksklusif } & \multicolumn{2}{|c|}{ Jumlah } & \multirow{3}{*}{$p$ value } \\
\hline & & \multicolumn{2}{|c|}{$\begin{array}{l}\text { 1 ldak } \\
\text { Eksklusif }\end{array}$} & \multicolumn{2}{|c|}{ ASI Eksklusif } & \multirow[t]{2}{*}{$\mathrm{N}$} & \multirow[t]{2}{*}{$\%$} & \\
\hline & & $\mathrm{N}$ & $\%$ & $\mathrm{~N}$ & $\%$ & & & \\
\hline 1 & Kurang & 16 & 66,7 & 8 & 33,3 & 24 & 100 & \\
\hline 2 & Baik & 7 & 13,7 & 44 & 86,3 & 51 & 100 & 0,000 \\
\hline Tota & & 23 & 30,7 & 52 & 69,3 & 75 & 100 & \\
\hline
\end{tabular}

Dari hasil uji statistik dengan menggunakan uji Chi square diperoleh $p$ value sebesar 0,000 yang berarti ada hubungan bermakna secara statistik antara pengetahuan Ibu tentang ASI Eksklusif dengan perilaku Ibu dalam pemberian ASI Eksklusif di Kelurahan Kesenden Wilayah Kerja UPTD Puskesmas Kejaksan Kota Cirebon Tahun 2013. 


\section{Hubungan Tingkat Pendidikan Ibu dengan Perilaku Ibu dalam Pemberian ASI Eksklusif}

Tabel 2. Hubungan Tingkat Pendidikan Ibu dengan Perilaku Ibu dalam Pemberian ASI Eksklusif

\begin{tabular}{|c|c|c|c|c|c|c|c|c|}
\hline \multirow{3}{*}{ No } & \multirow{3}{*}{$\begin{array}{l}\text { Tingkat Pendidikan } \\
\text { Ibu }\end{array}$} & \multicolumn{4}{|c|}{ Perilaku Pemberian ASI Eksklusif } & \multicolumn{2}{|c|}{ Jumlah } & \multirow{3}{*}{$p$ value } \\
\hline & & \multicolumn{2}{|c|}{$\begin{array}{l}\text { Tidak ASI } \\
\text { Eksklusif }\end{array}$} & \multicolumn{2}{|c|}{ ASI Eksklusif } & \multirow[t]{2}{*}{$\mathrm{N}$} & \multirow[t]{2}{*}{$\%$} & \\
\hline & & $\mathrm{N}$ & $\%$ & $\mathrm{~N}$ & $\%$ & & & \\
\hline 1 & Rendah & 12 & 31,6 & 26 & 68,4 & 38 & 100 & \multirow{3}{*}{1,000} \\
\hline 2 & Tinggi & 11 & 29,7 & 26 & 70,3 & 37 & 100 & \\
\hline Total & & 23 & 30,7 & 52 & 69,3 & 75 & 100 & \\
\hline
\end{tabular}

Dari hasil uji statistik dengan menggunakan uji Chi square diperoleh $p$ value sebesar 1,000 yang berarti tidak ada hubungan bermakna secara statistik antara tingkat pendidikan Ibu dengan perilaku Ibu dalam pemberian ASI Eksklusif di Kelurahan Kesenden Wilayah Kerja UPTD Puskesmas Kejaksan Kota Cirebon Tahun 2013.

\section{Hubungan Pekerjaan Ibu dengan Perilaku Ibu dalam Pemberian ASI Eksklusif}

Tabel 3. Hubungan Pekerjaan Ibu dengan Perilaku Ibu dalam Pemberian ASI Eksklusif

\begin{tabular}{|c|c|c|c|c|c|c|c|c|}
\hline \multirow{3}{*}{ No } & \multirow{3}{*}{ Status Bekerja Ibu } & \multicolumn{4}{|c|}{ Perilaku Pemberian ASI Eksklusif } & \multicolumn{2}{|c|}{ Jumlah } & \multirow{3}{*}{$p$ value } \\
\hline & & \multicolumn{2}{|c|}{$\begin{array}{l}\text { Tidak ASI } \\
\text { Eksklusif }\end{array}$} & \multicolumn{2}{|c|}{ ASI Eksklusif } & \multirow[t]{2}{*}{$\mathrm{N}$} & \multirow[t]{2}{*}{$\%$} & \\
\hline & & $\mathrm{N}$ & $\%$ & $\mathrm{~N}$ & $\%$ & & & \\
\hline 1 & Bekerja & 7 & 36,8 & 12 & 63,2 & 19 & 100 & 0,698 \\
\hline 2 & Tidak Bekerja & 16 & 28,6 & 40 & 71,4 & 56 & 100 & \\
\hline Tot: & & 23 & 30,7 & 52 & 69,3 & 75 & 100 & \\
\hline
\end{tabular}

Hasil uji statistik dengan menggunakan uji Chi square diperoleh nilai $p$ value sebesar 0,698 yang berarti tidak ada hubungan bermakna secara statistik antara status pekerjaan Ibu dengan perilaku Ibu dalam pemberian ASI Eksklusif di Kelurahan Kesenden Wilayah Kerja UPTD Puskesmas Kejaksan Kota Cirebon Tahun 2013.

\section{Hubungan Keterpaparan Informasi Ibu tentang Pemberian ASI eksklusif}

Tabel 4. Hubungan Keterpaparan Informasi Ibu tentang Pemberian ASI Eksklusif dengan Perilaku Ibu dalam Pemberian ASI Eksklusif

\begin{tabular}{|c|c|c|c|c|c|c|c|c|}
\hline \multirow{3}{*}{ No } & \multirow{3}{*}{$\begin{array}{l}\text { Keterpaparan } \\
\text { Informasi Ibu }\end{array}$} & \multicolumn{4}{|c|}{ Perilaku Pemberian ASI Eksklusif } & \multicolumn{2}{|c|}{ Jumlah } & \multirow{3}{*}{$p$ value } \\
\hline & & \multicolumn{2}{|c|}{$\begin{array}{l}\text { Tidak ASI } \\
\text { Eksklusif }\end{array}$} & \multicolumn{2}{|c|}{ ASI Eksklusif } & \multirow[t]{2}{*}{$\mathrm{N}$} & \multirow[t]{2}{*}{$\%$} & \\
\hline & & $\mathrm{N}$ & $\%$ & $\mathrm{~N}$ & $\%$ & & & \\
\hline 1 & Tidak Terpapar & 4 & 44,4 & 5 & 55,6 & 9 & 100 & \multirow[t]{3}{*}{0,003} \\
\hline 2 & Terpapar & 19 & 28,8 & 47 & 71,2 & 66 & 100 & \\
\hline Tot: & & 23 & 30,7 & 52 & 69,3 & 75 & 100 & \\
\hline
\end{tabular}

Hasil uji statistik dengan menggunakan uji Chi square diperoleh nilai $p$ value sebesar 0,003 yang berarti ada hubungan bermakna secara statistik antara keterpaparan informasi Ibu tentang ASI Eksklusif dengan perilaku Ibu dalam pemberian ASI Eksklusif di Kelurahan Kesenden Wilayah Kerja UPTD Puskesmas Kejaksan Kota Cirebon Tahun 2013. 


\section{Hubungan Dukungan Keluarga kepada Ibu untuk memberikan ASI eksklusif dengan Perilaku Ibu dalam Pemberian ASI Eksklusif}

Tabel 5. Hubungan Dukungan Keluarga kepada Ibu untuk memberikan ASI Eksklusif dengan Perilaku Ibu dalam Pemberian ASI Eksklusif

\begin{tabular}{|c|c|c|c|c|c|c|c|c|}
\hline \multirow{3}{*}{ No } & \multirow{3}{*}{$\begin{array}{l}\text { Dukungan Keluarga } \\
\text { terhadap Ibu }\end{array}$} & \multicolumn{4}{|c|}{ Perilaku Pemberian ASI Eksklusif } & \multicolumn{2}{|c|}{ Jumlah } & \multirow{3}{*}{$p$ value } \\
\hline & & \multicolumn{2}{|c|}{$\begin{array}{l}\text { Tidak ASI } \\
\text { Eksklusif }\end{array}$} & \multicolumn{2}{|c|}{ ASI Eksklusif } & \multirow[t]{2}{*}{$\mathrm{N}$} & \multirow[t]{2}{*}{$\%$} & \\
\hline & & $\mathrm{N}$ & $\%$ & $\mathrm{~N}$ & $\%$ & & & \\
\hline 1 & Tidak mendukung & 5 & 41,7 & 7 & 56,3 & 12 & 100 & \multirow{3}{*}{0,004} \\
\hline 2 & Mendukung & 16 & 28,6 & 45 & 71,4 & 63 & 100 & \\
\hline Total & & 23 & 30,7 & 52 & 69,3 & 75 & 100 & \\
\hline
\end{tabular}

Hasil uji statistik dengan menggunakan uji Chi square diperoleh $p$ value sebesar 0,004 yang berarti ada hubungan bermakna secara statistik antara dukungan keluarga dengan perilaku Ibu dalam pemberian ASI Eksklusif di Kelurahan Kesenden Wilayah Kerja UPTD Puskesmas Kejaksan Kota Cirebon Tahun 2013.

\section{Hubungan Dukungan Tenaga Kesehatan dengan Perilaku Ibu dalam Pemberian ASI Eksklusif}

Tabel 6. Hubungan Dukungan Tenaga Kesehatan dengan Perilaku Ibu dalam Pemberian ASI Eksklusif

\begin{tabular}{|c|c|c|c|c|c|c|c|c|}
\hline \multirow{3}{*}{ No } & \multirow{3}{*}{$\begin{array}{l}\text { Dukungan Tenaga } \\
\text { Kesehatan Ibu }\end{array}$} & \multicolumn{4}{|c|}{ Perilaku Pemberian ASI Eksklusif } & \multicolumn{2}{|c|}{ Jumlah } & \multirow{3}{*}{$p$ value } \\
\hline & & $\begin{array}{l}\text { Tidak ASI } \\
\text { Eksklusif }\end{array}$ & & \multicolumn{2}{|c|}{ ASI Eksklusif } & \multirow[t]{2}{*}{$\mathrm{N}$} & \multirow[t]{2}{*}{$\%$} & \\
\hline & & $\mathrm{N}$ & $\%$ & $\mathrm{~N}$ & $\%$ & & & \\
\hline 1 & Tidak Mendukung & 3 & 27,3 & 8 & 72,7 & 24 & 100 & 1,000 \\
\hline 2 & Mendukung & 20 & 31,3 & 44 & 68,8 & 51 & 100 & \\
\hline Tota & & 23 & 30,7 & 52 & 69,3 & 75 & 100 & \\
\hline
\end{tabular}

Hasil uji statistik dengan menggunakan uji Chi square diperoleh $p$ value sebesar 1,000 yang berarti tidak ada hubungan bermakna secara statistik antara dukungan tenaga kesehatan kepada Ibu untuk memberikan ASI Eksklusif dengan perilaku Ibu dalam pemberian ASI Eksklusif di Kelurahan Kesenden Wilayah Kerja UPTD Puskesmas Kejaksan Kota Cirebon Tahun 2013.

\section{PEMBAHASAN}

Hubungan Pengetahuan Ibu tentang Pemberian ASI Eksklusif dengan Perilaku Ibu dalam Pemberian ASI Eksklusif

Dari hasil uji statistik didapatkan nilai $p$ value sebesar 0,000 sehingga dapat disimpulkan bahwa ada hubungan bermakna antara pengetahuan Ibu tentang ASI Eksklusif dengan perilaku Ibu dalam pemberian ASI Eksklusif di Kelurahan Kesenden Wilayah Kerja UPTD Puskesmas Kejaksan Kota Cirebon Tahun 2013. Hasil penelitian ini didukung pula oleh teori dari Notoatmodjo (2007) yang menerangkan bahwa Pengetahuan merupakan faktor presdisposisi yang menentukan perilaku kesehatan seseorang. Dengan memiliki pengetahuan, seseorang akan lebih yakin dan percaya terhadap apa yang akan dilakukannya, serta lebih mengetahui apa akibatnya jika hal itu dilakukan atau tidak dilakukan. ${ }^{7}$ Penelitian ini sejalan dengan penelitian yang dilakukan oleh Irnawati (2011) yang menemukan adanya hubungan antara pengetahuan ibu dengan pemberian ASI Eksklusif pada bayi. ${ }^{8}$ 


\section{Hubungan Tingkat Pendidikan Ibu dengan Perilaku Ibu dalam Pemberian ASI Eksklusif}

Dari hasil uji statistik didapatkan nilai $p$ value sebesar 1,000 sehingga dapat disimpulkan bahwa tidak ada hubungan bermakna antara tingkat pendidikan Ibu dengan perilaku Ibu dalam pemberian ASI Eksklusif di Kelurahan Kesenden Wilayah Kerja UPTD Puskesmas Kejaksan Kota Cirebon Tahun 2013.

Penelitian ini sejalan dengan pendapat Van Esternik (1990) dalam artikel mengenai Pro dan Kontra ASI dan Susu Formula, yang menyatakan bahwa di negara maju praktek pemberian ASI memang banyak dilakukan oleh wanita-wanita berpendidikan tinggi tetapi ternyata untuk negara berkembang peningkatan pendidikan, kemampuan baca tulis, kesempatan menambah pendapatan, dan kemungkinan untuk memperoleh fasilitas perawatan kesehatan ada hubungan dengan berkurangnya prakara serta lama menyusui, atau mereka merasa dapat merawat anaknya lebih baik dengan cuma bekerja sehingga penghasilannya dapat digunakan untuk membeli makanan yang bermutu bagi anak mereka. Pernyataan ini diperkuat dari hasil penelitian WHO yang ada dalam buku van estermik menyatakan bahwa wanita yang berpendidikan menyusui bayinya tidak sesering dan tidak selama waktunya dengan apa yang dilakukan oleh para wanita miskin di daerah pedesaan dan perkotaan di negara berkembang. ${ }^{9}$

Penelitian ini sejalan dengan penelitian yang dilakukan oleh Sinta Purnamawati (2003) yang menemukan tidak adanya hubungan antara tingkat pendidikan ibu dengan pemberian ASI Eksklusif pada bayi. ${ }^{10}$

\section{Hubungan Pekerjaan Ibu dengan Perilaku Ibu dalam Pemberian ASI Eksklusif}

Dari hasil uji statistik didapatkan nilai pvalue sebesar 0,698 sehingga dapat disimpulkan bahwa tidak ada hubungan bermakna secara statistik antara status pekerjaan Ibu dengan perilaku Ibu dalam pemberian ASI Eksklusif di Kelurahan Kesenden Wilayah Kerja UPTD Puskesmas Kejaksan Kota Cirebon Tahun 2013.

Di kota-kota besar ada kecenderungan makin banyak ibu yang tidak memberikan ASI dengan salah satu penyebabnya adalah banyaknya ibu-ibu yang bekerja, dapat terlihat bahwa ibu yang bekerja sering dihadapkan pada satu masalah, karena harus meningkatkan bayinya dalam jangka waktu tertentu sehingga keberhasilan dalam memberikan ASI Eksklusif akan terganggu. Penelitian ini sejalan dengan penelitian yang dilakukan oleh Sinta Purnamawati (2003) yang menemukan tidak adanya hubungan antara pekerjaan ibu dengan pemberian ASI Eksklusif pada bayi. ${ }^{10}$

Penelitian ini tidak sejalan dengan penelitian yang dilakukan oleh Irnawati (2011) yang menemukan adanya hubungan anatara pekerjaan dengan pemberian ASI Eksklusif pada bayi $^{8}$. Namun pada penelitian ini ternyata ibu yang tidak bekerja dan tinggal di rumah pun tidak menjamin untuk memberikan ASI Eksklusif pada bayinya hal ini disebabkan karena adanya adat yang kuat yang membiasakan memberikan makanan tambahan pada bayi sebelum umur 6 bulan.

\section{Hubungan Keterpaparan Informasi Ibu tentang Pemberian ASI eksklusif}

Dari hasil uji statistik didapatkan nilai pvalue sebesar 0,003 sehingga dapat disimpulkan bahwa ada hubungan bermakna antara keterpaparan informasi Ibu tentang ASI Eksklusif dengan perilaku Ibu dalam pemberian ASI Eksklusif di Kelurahan Kesenden Wilayah Kerja UPTD Puskesmas Kejaksan Kota Cirebon Tahun 2013.

Penelitian ini sejalan dengan teori menurut Green dalam Notoatmodjo (2007) yang mengatakan bahwa faktor keterpaparan ibu terhadap sumber informasi tentang ASI pada 
waktu prenatal memberi pengaruh terhadap perilaku pemberian ASI karena faktor tersebut merupakan faktor reinforcing.

Penelitian ini sejalan dengan penelitian yang dilakukan oleh Sinta Purnamawati (2003) yang menemukan bahwa adanya hubungan yang signifikan antara keterpaparan informasi ibu dengan pemberian ASI Eksklusif pada bayi. ${ }^{10}$

\section{Hubungan Dukungan Keluarga kepada Ibu untuk memberikan ASI eksklusif}

Dari hasil uji statistik didapatkan nilai $p$ value sebesar 0,004 sehingga dapat disimpulkan bahwa ada hubungan bermakna antara dukungan keluarga dengan perilaku Ibu dalam pemberian ASI Eksklusif di Kelurahan Kesenden Wilayah Kerja UPTD Puskesmas Kejaksan Kota Cirebon Tahun 2013.

Penelitian ini sejalan dengan teori yang dikeluarkan oleh Green (2005), yang menyatakan bahwa perilaku seseorang dapat dipengaruhi oleh keluarga, karena itu keluarga termasuk kedalam faktor reinforcing (faktor Penguat). Jadi keluarga adalah salah satu pemberi dorongan yang terdekat pada ibu menyusui. Bahwa ada hubungan bermakna antara pemberian ASI dengan dukungan Keluarga. ${ }^{7}$

Penelitian ini sejalan dengan penelitian yang dilakukan oleh Irnawati (2011) yang menemukan adanya hubungan antara dukungan keluarga dengan pemberian ASI Eksklusif pada bayi. ${ }^{8}$

\section{Hubungan Dukungan Tenaga Kesehatan dengan Perilaku Ibu dalam Pemberian ASI Eksklusif}

Dari hasil uji statistik didapatkan nilai pvalue sebesar 1,000 sehingga dapat disimpulkan bahwa tidak ada hubungan bermakna secara statistik antara dukungan tenaga kesehatan kepada Ibu untuk memberikan ASI Eksklusif dengan perilaku Ibu dalam pemberian ASI Eksklusif di Kelurahan Kesenden Wilayah Kerja UPTD Puskesmas Kejaksan Kota Cirebon Tahun 2013.

Petugas kesehatan yang memberikan dukungan pada ibu menyusui tidak menjamin ibu akan memberikan ASI nya hal ini dikarenakan bahwa perilaku ibu untuk menyusui secara ASI Eksklusif tidak hanya dipengaruhi oleh satu faktor saja seperti dukungan petugas kesehatan saja melainkan dukungan keluargalah yang lebih besar dalam memberikan motivasi bagi ibu karena Ibu yang baru melahirkan biasanya masih merasa lemah baik secara fisik dan psikis dan butuh waktu untuk memulihkan pada kondisi semula sehingga ibu lebih membutuhkan dukungan keluarga yang merupakan faktor paling kuat dalam support system bagi ibu dan yang lebih dirasakan dalam mendukung ibu untuk memberikan ASI Eksklusif pada bayinya.

Penelitian ini tidak sejalan dengan penelitian yang dilakukan oleh Irnawati (2011) yang menemukan adanya hubungan antara dukungan petugas kesehatan dengan pemberian ASI Eksklusif. $^{8}$

\section{SIMPULAN}

1. Ada hubungan bermakna antara pengetahuan ibu bayi tentang ASI Eksklusif dengan perilaku ibu dalam pemberian ASI Eksklusif di Kelurahan Kesenden Wilayah Kerja UPTD Puskesmas Kejaksan Kota Cirebon Tahun 2013.

2. Tidak ada hubungan bermakna antara tingkat pendidikan ibu bayi dengan perilaku ibu dalam pemberian ASI Eksklusif di Kelurahan Kesenden Wilayah Kerja UPTD Puskesmas Kejaksan Kota Cirebon Tahun 2013.

3. Tidak ada hubungan bermakna antara pekerjaan ibu bayi dengan perilaku ibu dalam pemberian ASI Eksklusif di Kelurahan Kesenden Wilayah Kerja UPTD Puskesmas Kejaksan Kota Cirebon Tahun 2013. 
4. Ada hubungan bermakna antara keterpaparan informasi ibu bayi tentang ASI Eksklusif dengan perilaku ibu dalam pemberian ASI Eksklusif di Kelurahan Kesenden Wilayah Kerja UPTD Puskesmas Kejaksan Kota Cirebon Tahun 2013.

5. Ada hubungan bermakna antara dukungan keluarga pada ibu bayi terhadap pemberian ASI Eksklusif dengan perilaku ibu dalam pemberian ASI Eksklusif di Kelurahan Kesenden Wilayah Kerja UPTD Puskesmas Kejaksan Kota Cirebon Tahun 2013.

6. Tidak ada hubungan bermakna antara dukungan tenaga kesehatan pada ibu bayi terhadap pemberian ASI Eksklusif dengan perilaku ibu dalam pemberian ASI Eksklusif di Kelurahan Kesenden Wilayah Kerja UPTD Puskesmas Kejaksan Kota Cirebon Tahun 2013.

\section{SARAN}

1. Bagi Dinas Kesehatan

Menyediakan media KIE seperti leaflet, booklet, poster, yang berkaitan dengan ASI Eksklusif yang dapat dimanfaatkan untuk penyuluhan dan pembinaan.

2. Bagi Puskesmas

1) Mengadakan pelatihan "Kader Motivation" tentang peningkatan penggunaan ASI Eksklusif dengan kedalaman materi yang sederhana sesuai dengan kemampuan dan tugas kader di lapangan yang bertujuan untuk meningkatkan pengetahuan kader dalam pemantauan kecenderungan pemberian ASI Eksklusif, sehingga kader dapat melakukan penyuluhan secara sederhana.

2) Untuk Manajemen di Puskesmas agar menyediakan dana untuk memasukkan penyuluhan mengenai ASI Eksklusif dari bantuan dana yang ada sebagai dana BOK.

3. Bagi Masyarakat

Segera konsultasikan ke pelayanan kesehatan (klinik laktasi) bagi ibu yang mengalami masalah laktasi atau menyusui serta menganjurkan pada ibu-ibu hamil untuk mendapatkan penyuluhan tentang ASI Eksklusif sebagai persiapan pada saat melahirkan nanti untuk memberikan ASI Eksklusif.

4. Bagi Mahasiswa/ Peneliti Lanjutan

Menambah variabel lain yang belum diteliti seperti umur, keterampilan petugas dan komitmen pemerintah untuk mendeteksi penyebab lain terjadinya masalah ibu bayi tidak memberikan ASI Eksklusif pada bayinya, khususnya di Kelurahan Kesenden Wilayah Kerja UPTD Puskesmas Kejaksan.

5. Bagi Instansi Pendidikan

Sebagai bahan penambah referensi pada penelitian-penelitian berikutnya dengan topik penelitian yang sama yaitu pemberian ASI Eksklusif.

\section{DAFTAR PUSTAKA}

1. Anonim. Air susu ibu segala manfaat kehidupan. Edisi1/tahun XII 2010, Jakarta : Pusat Promosi Kesehatan Kementrian Kesehatan RI; 2010.

2. Rusli Utami. Mengenal ASI Eksklusif. Rosmaida Karya, Bandung ; 2003.

3. Departemen Kesehatan RI. Keunggulan ASI dan Manfaat Menyusui. Buku Panduan Manajemen Laktasi. Jakarta ; 2003.

4. Puskesmas Kejaksan. Laporan Tahunan Program Gizi. Cirebon: UPTD Puskesmas Kejaksan; 2011

5. Arikunto.S Prosedur penelitian suatu pendekatan praktek, revisi V; Jakarta: Rineka Cipta; 2006

6. Puskesmas Kejaksan. Laporan Bulanan (LB3) Gizi, Bulan Agustus 2012. Cirebon: UPTD Puskesmas Kejaksan; 2012 
7. Notoatmodjo, Ilmu Perilaku Kesehatan. Jakarta. Rineka Cipta; 2007

8. Irnawati. Faktor-faktor yang berhubungan dengan pemberian ASI Eksklusif di Kelurahan Kecapi Kota Cirebon Tahun 2011. Cirebon. Skripsi. STIKes Cirebon;2011

9. Esternick,Penny, Van. Pro Kontra ASI susu Formula. Yayasan Obor Indonesia; 2003.

10. Sinta Purnamawati. Faktor-faktor yang berhubungan dengan Pola Pemberian ASI pada Bayi Usia Empat Bulan (Analisis Data Susenas 2001) Tahun 2003. Jakarta. Skripsi. FKM UI;2003 